\title{
Inferential seemings and the problem of reflective awareness
}

\author{
Luca Moretti \\ 1.moretti@abdn.ac.uk \\ University of Aberdeen \& Munich Center for Mathematical Philosophy
}

\begin{abstract}
Phenomenal conservatism (PC) is the internalist view that non-inferential justification rests on appearances. PC's advocates have recently argued that seemings are also required to explain inferential justification. The most general and developed view to this effect is Huemer (2016)'s theory of inferential seemings (ToIS). Moretti (2018) has shown that PC is affected by the problem of reflective awareness, which makes PC open to sceptical challenges. In this paper I argue that ToIS is afflicted by a version of the same problem and it is thus hostage to inferential scepticism. I also suggest a possible response on behalf of ToIS's advocates.
\end{abstract}

KEYWORDS Inferential justification; inferential seemings; phenomenal conservatism; reflective awareness; entitlement theory; Michael Huemer.

\section{Introduction}

Huemer $(2001,2007)$ has defended an internalist theory of non-inferential justification, nowadays very popular, called phenomenal conservatism (PC). Other epistemologists - prominently, Pryor $(2000,2004)$ - have supported similar views. According to PC, a subject $S$ 's seeming or appearance that $P$ gives $S$ defeasible, non-inferential justification for believing $P$. Some epistemologists — for instance Chudnoff (2014), Brogaard (2016) and Huemer (2016) — argue that appearances are also required to explain internalist inferential justification. The most developed of these views is Huemer (2016)'s theory of inferential seemings (ToIS). According to it, $S$ 's having inferential justification for $Q$ from $P$ requires $S$ to entertain an inferential appearance that represents $Q$ as being true or probably true in light of $P$. In Moretti (2018) I have argued that PC is affected by the problem of reflective awareness, which makes 
seeming-based non-inferential justification elusive and targetable by sceptical arguments. In this paper, I show that, despite its merits, ToIS is afflicted by a variant of this problem and it is thus hostage to a form of inferential scepticism. I explore possible strategies of response available to ToIS's advocates and I suggest that they might be able to resolve this problem if they combined ToIS with some version of epistemic entitlement theory.

In more detail, $\S 2$ outlines PC and the problem of reflective awareness. $\S 3$ introduces ToIS. $\S 4$ argues that ToIS is affected by the problem of reflective awareness. $\S 5$ contends that ToIS is open to a sceptical challenge. $\S 6$ outlines and appraises possible responses by ToIS's advocates. $§ 7$ concludes the paper.

\section{PC, scepticism and the problem of reflective awareness}

The claim that we have epistemic justification for believing many things just because of the ways things appear to us to be looks plausible. For instance, it looks plausible that I can have justification for believing that this is a hand just because it seems visually so to me. It looks plausible that I have a reason for believing that $1=1$ just because it seems a priori true to me. PC accounts for the justifying force of seemings by this principle: ${ }^{1}$

(JS) If it seems to $S$ that $P$, then, in the absence of defeaters, $S$ thereby has justification sufficient to believe $P^{2,3}$

${ }^{1}$ For more detailed introductions to PC, see Tucker (2013), Moretti (2015) and Huemer (2018).

2 JS has been introduced in Huemer (2001) and it is the principle actually at stake in most conversation about PC. Huemer (2007) defends a variant of JS according to which if it seems to $S$ that $P$, in the absence of defeaters $S$ has at least some degree of justification for believing $P$. Huemer fears that a weak and wavering seeming that $P$ couldn't give $S$ justification sufficient to believe $P$ (cf. [2007, 30n1]). To get round this difficulty, whenever I speak of seemings or appearances, I always mean clear and firm seemings.

${ }^{3}$ JS concerns propositional justification but it can easily be re-formulated to apply to doxastic justification (see for instance Huemer [2018]) 
Seemings are conceived of by PC's advocates as experiences provided with propositional content but unanalysable in terms of belief. Such experiences have an assertive phenomenology, described as the feeling of ascertaining that a given proposition is true (cf. Tolhurst [1998]; Huemer [2001, §4]; Pryor [2004]). Defeaters may be constituted by seemings, beliefs or other contentful mental states (cf. Huemer [2006, 148]). The 'thereby' in JS indicates that $S$ 's justification for $P$ is solely based on the seeming that $P$. Since it is based on no belief of $S$ (e.g., the belief that $S$ 's faculties are reliable or the reflective belief that $S$ has a seeming that $P$ ), this justification is noninferential (cf. Huemer [2018]).

$\mathrm{PC}$ is internalist at least in the sense of mentalist internalism, as the conditions that confer epistemic justification or rationality on $S$ supervene on $S$ 's psychological states — in particular, on $S$ 's appearances and lack of defeaters (cf. Huemer [2011]). Indeed, a central motivation for PC is its ability to account for internalist intuitions; for instance, the intuition that it cannot be the case that $P$ is justified for $S$ but $Q$ is not, when $P$ and $Q$ appear to $S$ to be exactly alike in all epistemically relevant respects (i.e., when $P$ and $Q$ appear equally plausible, the experiences supporting them appear equally trustworthy, and so on) (cf. Huemer [2006, 2011]).

One reason why PC is philosophically alluring is that it applies to seemings of any type and thus offers a unified account of non-inferential justification for beliefs of all sorts. ${ }^{4}$ In this way PC plays a key role in grounding fallible foundationalism (cf. Huemer [2001, 102]). A celebrated virtue of PC is also its antisceptical bite. Suppose $S$ experiences as if $(P)$ the cat is on the mat. The sceptic may insist that $S$ could acquire defeasible justification for believing $P$ from her experience only if $S$ had independent justification for disbelieving that, say, $(\mathrm{SH}) S^{\prime}$ 's experience is a hallucination induced by

\footnotetext{
${ }^{4}$ For instance, perceptual, a priori, moral, and mnemonic beliefs (cf. Moretti [2015]).
} 
the Matrix. The sceptic will contend that since $S$ cannot have this independent justification, $S$ has no justification for $P$. Suppose, however, that $S$ 's experience is a seeming. If $\mathrm{PC}$ is true, $S$ can have justification for believing $P$ even if she lacks independent justification for disbelieving $S H$ (cf. Huemer [2001]; Pryor [2000, 2004]). ${ }^{5}$

I find PC prima facie plausible. ${ }^{6}$ In Moretti (2018) I have shown that PC's antisceptical bite is significantly limited by the problem of reflective awareness. Let's tell apart ' $S$ 's having a seeming that $P$ ' and ' $S$ 's being reflectively aware of a seeming that $P^{\prime}$. The first expression refers to a mental state of $S$ - a seeming that $P$ - which could exist even if $S$ didn't reflect on her experiences. The second refers to a more complex state encompassing at least: (i) $S$ 's seeming that $P$, (ii) $S$ 's reflective acquaintance with her seeming, and (iii) $S$ 's reflective belief obtained through acquaintance that she has that seeming. Suppose $S$ has non-inferential justification for believing $P$ from her seeming that $P$. The problem of reflective awareness is this: if $S$ becomes reflectively aware of her seeming and realizes that its existence can potentially be explained by hypotheses incompatible with $P, S$ 's seaming-based justification for $P$ will be either simply defeated or replaced with inferential justification for $P$ that requires $S$ to have independent justification for disbelieving the error hypotheses.

For instance, imagine $S$ has a seeming that $(P)$ the cat is on the mat, and no defeater. If JS is correct, $S$ will thereby possess non-inferential justification for believing $P$. Suppose that at a time $t, S$ then becomes reflectively aware of her seeming. Before $t, S$ didn't have the belief that she had that seeming. $S$ was thus unable to wonder whether the seeming was veridical. At $t S$ can pose this question. Imagine $S$ does so. She will find alternative explanations of why she has that seeming: it might be the result of her actually perceiving that $P$, or an illusion or hallucination produced by a clever

\footnotetext{
${ }^{5}$ For other asserted virtues of PC see Tucker (2013).

${ }^{6} \mathrm{PC}$ has been targeted by various arguments but it is dubious it has been lethally struck. For objections and responses see Tucker (2013), Moretti (2015) and Huemer (2018).
} 
camouflage, a hallucinogenic inadvertently consumed, the Matrix, and so on. $S$ will realize that her seeming that $P$ might result from various states of affairs that falsify $P$. In these circumstances, if $S$ lacks independent justification for ruling out some of these possible explanations incompatible with $P$ as false or improbable, $S$ can no longer rationally believe $P$. S's justification for believing $P$ will thus be destroyed. ${ }^{7}$

Alternatively, if $S$ finds independent justification for ruling out all these error conjectures, her non-inferential justification for $P$ will be supplanted by inferential justification. For example, imagine $S$ has statistical evidence that each error conjecture

\footnotetext{
${ }^{7}$ A referee of this journal suggests that PC's advocates might try to reject this claim by insisting that:
}

(*) $S$ 's conceiving of a deceptive scenario $S H$ incompatible with $P$ need not defeat $S$ 's justification for $P$, unless $S$ has reason to think that $S H$ obtains or is likely to obtain. If (*) is correct, even if $S$ lacked independent justification for taking $S H$ to be false or improbable, $S$ could still have justification for believing $P$. The referee helpfully indicates that a general problem of $(*)$ is that it enables bootstrapping reasoning, which is counterintuitive. In short, once $S$ acquires justification for believing $P$ and competently deduces Not-SH from $P, S$ will acquire justification for believing Not-SH, and thus disbelieving $S H$. This appears to be a too easy way to earn justification for ruling out $S H$. (I return to bootstrapping in $\S 6$.) Another problem of $\left(^{*}\right)$ is that it has elementary counterexamples. Suppose $S$ conceived of a deceptive scenario $S H$ incompatible with $P$ and found equal reasons for $S H$ and Not-SH. (Imagine that $S$ found out that $S H$ and Not$S H$ have equal chance to obtain.) It is intuitive that $S$ 's appearance-based justification for believing $P$ would normally be defeated in these circumstances, though $S$ wouldn't have reason to think that $S H$ obtains or is likely to obtain (cf. Wright [2007, 41]; Pryor [2018, 139]). Irrespective of these considerations, $(*)$ appears false if one considers carefully the predicament of $S$ in the thought experiments illustrating the problem of reflective awareness. When $S$ comes to entertain the belief that she has a seeming that $P$ and conceives of an array of alternative and incompatible explanations of her seeming, $S$ could rationally believe one of these explanations only if she had independent reasons to disbelieve all the others. $S$ 's selecting one specific explanation without possessing such reasons would be arbitrary. This looks straightforward. Consequently, $S$ could justifiedly believe the specific explanation according to which she perceives that $P$ (and so she could justifiedly believe $P$ ) only if she had independent justification for taking the other error explanations to be false or improbable. 
is extremely unlikely. Or suppose $S$ realizes that all error conjectures are exceedingly complicated and far-fetched, and that this constitutes evidence that they are all very unlikely. In either case, by adducing her justified beliefs about the low probability of the error conjectures, $S$ may be able to justifiedly conclude via reasoning that $P$ is true or probably true. $S$ 's non-inferential justification for believing $P$ will in this case be replaced by inferential justification. Furthermore, this inferential justification will require $S$ to possess independent justification for disbelieving all error conjectures.

Now consider again a sceptical argument that assumes that $S$ must have independent justification for ruling out any relevant error conjecture in order to acquire justification from her experience, and that concludes that $S$ cannot acquire justification from experience because she cannot have that independent justification. In the face of this argument, if $\mathrm{PC}$ is true and experiences are appearances, ordinary people unaccustomed to reflecting on their experiences and subjects incapable of doing so (e.g., small children) will normally possess experience-based justification. For, if PC is true, possessing this justification doesn't depend on having independent justification for ruling out error conjectures. Nevertheless, PC won't benefit reflective subjects (e.g., epistemologists) who engage with sceptical arguments of the type described above in the attempt to refute them (cf. Moretti 2018). Suppose $S$ aimed at refuting an argument stating that since $S$ 's appearance as if $P$ might result from the truth of a conjecture $S H$ incompatible with $P, S$ could acquire justification for $P$ only if she had independent justification for disbelieving $S H$. $S$ could actually engage with this argument only if she grasped the way in which it applies to her epistemic circumstances - so, only if $S$ were reflectively aware of her seeming that $P$ and realized that $S H$ is a potential explanation of it. Once these two conditions were fulfilled, despite PC, $S$ could have justification for believing $P$ only if she had independent justification for disbelieving $S H$, which is what the sceptic contends. 


\section{Huemer's ToIS}

Huemer $(2016)^{8}$ distinguishes between fully explicit inference and inference against background. Suppose $S$ infers $P$ from $E$ (where $E$ can be a conjunction of propositions). What differentiates these two kinds of inferences is this: in the first case $S$ needs no (non-logical) background information to draw the inference and attain justification for $P$; in the second, $S$ needs some background information to make the inference and attain justification for $P$ (cf. [2016, 144]).

For example, suppose $S$ justifiedly believes that $(E)$ it is false that both a tiger and a cow are on the couch, and that from this $S$ justifiedly infers that $(P)$ there is no tiger or no cow on the couch. $S$ will need some background to understand $E$ and $P$. But $S$ 's ability to perform the inference and $S$ 's justification for $P$ don't require any (nonlogical) background. Thus, this counts as a fully explicit inference. Alternatively, imagine $S$ returns home and sees that the couch's fabric is shredded. From her justified belief that $(E)$ the cat has been home all the time and the couch's fabric has become shredded, $S$ justifiedly infers that $(P)$ the cat has shredded the fabric. $S$ 's ability to run this inference and her justification for $P$ require a host of background beliefs (which needn't be occurrent in $S$ 's mind). $S$ needs to believe, for instance, that the cat has sharp claws and fabric doesn't spontaneously become shredded. This is an inference against background (cf. [2016, 144]).

ToIS accounts for inferential justification resting on, indifferently, fully explicit inferences or inferences against background, where these inferences can be deductive or non-deductive. Justification is meant to be doxastic, which requires $S$ to believe both $E$ and $P$, and consciously infer $P$ from $E$ (cf. [2016, 144-145]). A key assumption of ToIS is that $S$ 's acquiring an inferentially justified belief that $P$ from another justified belief

\footnotetext{
${ }^{8}$ ToIS was already presupposed in some of Huemer's earlier work — for instance, Huemer
} (2001, 112-113, 2007, 30n1). 
that $E$ requires $S$ to have an appearance — called inferential seeming — which represents $P$ as being true or probably true given or in light of $E^{9}$ (cf. $[2016,153]$ ). ToIS rests on the same internalist intuition that underlies $\mathrm{PC}$, according to which there is an essential link between what is epistemically justified or rational for $S$ and her psychological states. The latter states include in this case $S$ 's inferential appearances (cf. Huemer [2013, 339]).

Let me first outline ToIS's account of inferential justification resting on fully explicit inference. It says that $S$ 's belief that $P$ is inferentially justified to some degree just in case there is a proposition $E$ such that:

(1) $S$ 's belief that $E$ is justified to some degree;

(2) $S$ has an inferential seeming that, in light of $E, P$ is true or probably true;

(3) $S$ 's justification for $E$ doesn't depend on $S$ 's having justification for $P$;

(4) $S$ lacks (robust) defeaters for $P$;

(5) $S$ 's belief that $E$ causes $S$ 's belief that $P$ via $S$ 's inferential seeming and by a non-deviant causal chain. (Cf. [2016, 150])

Although this account concerns degrees of justification, I take it to entail the following about plain justification: $S$ 's belief that $P$ is inferentially justified if and only if $S$ 's belief that $E$ is justified and (2)-(5) are satisfied.

(1), (3) and (4) are obviously required. (1) looks basic. (3) rules out questionbegging inferences. (4) is needed because $S$ would lack inferential justification for $P$ if $S$ had a defeater of that justification. ${ }^{10}$

\footnotetext{
9 An inferential seeming doesn't merely represent that $E$ and $P$ stand in a certain logical or epistemic relation to one other. Huemer fears that a seeming of this type would engender a variant of Lewis Carroll's infinite regress problem (cf. [2016, 146-147, 152-153]). For Huemer, an inferential seeming is rather one that represents that $P$ is true or probable under the assumption that $E$ is true (cf. [2016: 149-150]).

${ }^{10}$ A robust defeater is one capable of making $P$ completely unjustified (cf. [2016, 151]). If we focus on plain justification rather than degrees of it, the qualification 'robust' is irrelevant.
} 
Conditions (2) and (5) call for elucidation. Huemer endorses the principle widespread among internalists — that $S$ can acquire an inferentially justified belief that $P$ from another belief that $E$ of her only if (a) $S$ sees (in some relevant sense) ${ }^{11}$ that $E$ supports $P$ (i.e., that $E$ makes $P$ true or probable) and (b) $S$ infers $P$ from $E$ through seeing that $E$ supports $P$. Condition (2) fleshes out the requirement (a) by interpreting ' $S$ sees that...' as ' $S$ has an inferential seeming that...' (cf. [2016, 150-151, 2013, 338]).

One could criticize Huemer's interpretation of ' $S$ sees that...' by highlighting that $S$ might mistakenly happen to have a seeming that $E$ supports $P$ when $E$ does not support $P$. Huemer dismisses this criticism observing that it rests on the questionable assumption that $S$ 's having an inferentially justified belief that $P$ from a belief that $E$ requires $E$ to actually support $P$. He contends - plausibly, in my opinion - that from an internalist viewpoint, $S$ 's inferentially justified belief doesn't require actual support. Consider a skilled but unfortunate mathematician who has carefully completed an apparent proof that $P$ from premise $E$ by making an undetected, subtle mistake. Since $E$ appears to entail $P$ to the mathematician, and she finds no reason whatsoever to think of the contrary, the mathematician is inferentially justified in believing $P$. It would be irrational for her not to believe $P$ in these circumstances (cf. [2016, 147-148, 2013, 339]).

Condition (5) fleshes out the internalist constraint on inferentially justified belief according to which (b) $S$ must infer $P$ from $E$ through her seeing that $E$ supports $P$. Accordingly, (5) requires that $S$ 's belief that $E$ must cause $S$ 's belief that $P$ - in a nondeviant way $^{12}$ — via $S$ 's seeming that $E$ supports $P$ (cf. [2016, 151-152, 2013, 338]).

${ }^{11}$ I follow Huemer (2016) in taking the verb to see not to be necessarily factive in this context.

${ }^{12}$ It is notoriously difficult to give a characterization of a deviant causal link. Huemer provides this example: $S$ justifiedly believes $E$ and sees that $E$ supports $P$, but she refuses to believe $P$ because this makes her unhappy. Nevertheless, an epistemically benevolent brain scientist detects $S$ 's justified belief that $E$ and $S$ 's inferential appearance. And this 
Let's turn to ToIS's account of inferential justification resting on inference against background. Suppose $S$ infers $P$ from $E$ against background information $B$. On Huemer's account, $S$ will entertain a seeming that $E$ supports $P$. How does $B$ come into this picture? It is implausible that $S$ 's seeming could represent $P$ as true or probably true given $E$ and $B$. For the information stored in one's background information doesn't normally become occurrent in one's mind either in the form of belief or in the form of appearance (cf. [2016, 157]). ToIS explains the epistemic relevance of $B$ as follows: the truth or probability referred to in $S$ 's inferential seeming is relativized to $B$ in the same sense in which confirmation theorists say that the probability of a proposition given evidence is conditioned on background information (cf. [2016, 157-158]). But how can $S$ 's seeming include reference to $B$ if $S$ isn't conscious of $B$ ? Firstly, $S$ 's seeming is generated by brain processes shaped by $B$. Furthermore, $S$ will be disposed, if the issue arises, to acknowledge the relevance of $B$ to her appearance's content (cf. $[2016,158])$.

ToIS's account of inferential justification resting on inference against background comes in terms of conditions (1)-(5) with (2) is supplanted by:

$\left(2^{\mathrm{B}}\right) S$ has an inferential seeming that, in light of $E, P$ is true or probably true relative to $B$.

This summary has hopefully shown that ToIS is interesting and prima facie plausible or promising. To complete my presentation, let me contrast ToIS with Fumerton's rival theory. Fumerton $(1995,36,85-94,187-224)$ also adopts an internalist approach to justification and maintains that $S$ is inferentially justified in believing $P$ on the basis of $E^{13}$ only if: (1*) $S$ is justified in believing $E$ and (2*) $S$ is justified in believing that $E$ makes $P$ true or probable because, among other things, $\left(3^{*}\right) S$ is

detection causes the scientist to use a brain-manipulation tool to induce in $S$ a belief that $P$. Clearly, $S$ 's belief that $P$ isn't in this case inferential.

${ }^{13}$ Where $E$ includes everything that $S$ takes to be relevant to $P$ 's truth. 
acquainted with the logical probability of $P$ given $E$. Fumerton endorses classical acquaintance theory according to which $S$ is acquainted with a fact when it is immediately before $S$ 's consciousness. He thinks of logical probability in Keynesian terms, as a sui generis abstract relation between propositions (where entailment is the upper limit of making probable). Fumerton (2015) concedes that (2*) may be dropped. ToIS and Fumerton's thus essentially diverge because of $(3 *)$. Whereas Huemer interprets the internalist requirement for inferential justification that $S$ must see that $E$ supports $P$ as stating that $S$ must have a seeming that $E$ supports $P$, Fumerton interprets it as saying that $S$ must be acquainted with the (high) logical probability of $P$ given $E$.

An advantage of ToIS over Fumerton's theory is that it doesn't rest on the controversial thesis that there exist logical probabilities. $S$ 's inferential seeming represents $P$ as true or probably true given $E$, but 'probably true' need not be interpreted as referring just to logical probability - any interpretation of it suitable to flesh out the intuition that $S$ sees that $E$ supports $P$ would do (cf. Huemer [2016, 154$155,159])$. In addition, note that acquaintance is factive $-S$ cannot be acquainted with the fact that $P$ 's logical probability given $E$ is high unless this probability is actually so - whereas appearance can be non-veridical $-S$ can have the appearance that $E$ supports $P$ when it doesn't. So Fumerton's theory cannot explain the cases in which $S$ has an inferentially justified belief that $P$ from another belief that $E$, though $E$ doesn't really support $P$. (Recall the case of the unfortunate mathematician.) ToIS doesn't have this problem (cf. [2016, 155-156]).

\section{Inferential seemings and the problem of reflective awareness}

Once inferential seemings are called on, a version of the problem of reflective awareness surfaces. Imagine that $S$ has a justified belief that $E$, an inferential seeming that $E$ supports $P$ (perhaps relative to some background $B$ ), and no reason for disbelieving $P$ or distrusting her seeming. If $S$ comes to believe $P$ because of her 
justified belief that $E$ via her seeming that $E$ supports $P, S$ 's belief that $P$ will be inferentially justified. Nevertheless, if $S$ becomes reflectively aware of her seeming that $E$ supports $P$ and realizes that its existence can potentially be explained by conjectures incompatible with the truthfulness of the seeming, the justification of her belief that $P$ will be either destroyed or supplanted by new inferential justification requiring $S$ to have independent justification for believing that her seeming is trustworthy.

Let me illustrate this with an example. Suppose $S$ justifiedly entertains a belief that $(E)$ it is false that both a tiger and a cow are on the couch. Furthermore, imagine that $S$ has an inferential seeming that given $E$ it is true that $(P)$ there is no tiger or no cow on the couch, and no evidence for disbelieving $P$ or distrusting her seeming. Since $S$ comes to believe $P$ because of $E$ and through her seeming that $P$ is true given $E, S$ 's belief that $P$ is inferentially justified. However, suppose that at a time $t S$ becomes reflectively aware of her inferential seeming. Accordingly, $S$ will entertain a reflective belief that she has a seeming that $P$ is true given $E$. Before $t S$ didn't have this belief, so $S$ was incapable of wondering whether her appearance was veridical or deceptive. But at $t, S$ can ask herself this question. Imagine $S$ does so. She will find various possible responses: that appearance might result from her actual ascertaining that $P$ is true given $E$ through some analytic or intuitive faculty she is endowed with. Alternatively, the seeming might be a deceptive representation produced by, for instance, $S$ 's sheer tiredness, a cognitive impairment of $S$ caused by an incipient mental disorder, a Cartesian demon, ${ }^{14}$ and so on. After $t S$ will thus realize that her seeming that $P$ is true in light of $E$ can possibly be explained by hypotheses that entail that it is false that $P$ is true in light of $E$.

${ }^{14}$ In his First Meditation Descartes introduces the conjecture of a deceiving God, then reformulated as the demon conjecture, which raises the possibility that we might constantly be deceived in our elementary arithmetical reasoning. It is easy to extend this conjecture to threaten all our elementary inferences. 
Suppose $S$ found no justification for ruling out as false or improbable some of the error explanations she has conceived of. Without this independent justification, $S$ couldn't rationally believe the hypothesis that her inferential seeming results from her actually ascertaining that $P$ is true in light of $E$. Thus, despite her justified belief that $E$ and her seeming that $E$ supports $P, S$ couldn't justifiedly believe $P .{ }^{15}$

Alternatively, suppose $S$ found justification for ruling out any of these error hypotheses and concluding that her inferential seeming is veridical or trustworthy. In this case $S$ 's belief that $P$ would still be inferentially justified. However, now the inferential justification of $S$ 's belief that $P$ would depend on both $S$ 's original justified belief that $E$ and $S$ 's independently justified belief that her seeming is veridical.

I have considered a fully explicit inference relying on a deductive seeming, but my example can be recast using inferences of other types. For instance, take again $S$ 's abductive inference against background going from

(E) The cat has been home all the time and the couch's fabric has become shredded to

$(P)$ The cat has shredded the fabric.

Suppose that $S$ justifiedly believes $E$, has an inferential - abductive — seeming that $P$ is probably true given $E$ relative to background $B,{ }^{16}$ and no reason to disbelieve $P$ or doubt the truthfulness of her seeming. Suppose $S$ thereby believes $P$. $S$ 's belief will

${ }^{15}$ A referee of this journal suggests that advocates of ToIS might respond that in order to rationally believe $P, S$ need not have independent justification for ruling out the error conjectures she has conceived of, at least so long as $S$ doesn't have a seeming that an error conjecture is likely. I find this possible response misguided. In the circumstances I've described, $S$ can rationally believe $P$ on the basis of $E$ only if she has an epistemic reason to prefer the hypothesis that her inferential seeming is veridical to any alternative error hypothesis she has conceived of. To do so, $S$ does need independent justification for ruling out all these alternatives.

${ }^{16}$ Hereafter, I leave reference to $B$ implicit. 
be inferentially justified. Imagine that at a time $t, S$ then acquires a reflective belief that she has that inferential seeming. $S$ will be able to wonder whether the seeming is trustworthy or not. If $S$ does so, $S$ will find some possible responses: $S$ might hypothesize that her seeming is trustworthy because it has been produced by a faculty she is endowed with that tracks the actual probability of propositions given evidence. ${ }^{17}$ Once $S$ has posited an explanation of this sort, $S$ will also conceive of alternative explanations that imply that her seeming is deceptive. $S$ might conjecture that the faculty she is supposedly endowed with is faulty on that occasion because, say, $S$ is unconsciously biased against cats, $S$ has inadvertently ingested LSD, or a Cartesian demon has interfered. $S$ might also conceive of error conjectures entailing that no faculty like the one imagined actually exists. After $t S$ will thus realize that her seeming that $P$ is probable in light of $E$ can possibly be explained by conjectures that entail that it is false that $P$ is probable in light of $E$.

Suppose $S$ lacks justification for ruling out some of these error conjectures. $S$ 's belief that $P$ would no longer be justified. Alternatively, suppose that $S$ finds justification for ruling out all these error conjectures, to conclude that her seeming is trustworthy. It is intuitive that in this case $S$ 's belief that $P$ would still be inferentially justified. But now the inferential justification of $S$ 's belief that $P$ would depend on both $S$ 's original belief that $E$ and S's independently justified belief that her seeming that $E$ supports $P$ is trustworthy.

17 A controversial hypothesis, which Huemer (2016) nevertheless appears to flirt with, is that non-deductive inferential appearances depend on a faculty of $S$ that tracks logical probabilities. 'Probability' could also be interpreted subjectively. In this interpretation, inferential seemings are not requested to track logical relations or objective chances. However, note that subjective probabilities must be coherent - they must conform to the probability calculus. In this interpretation, inferential seemings must depend on some cognitive faculty that guarantees this (weak) form of objectivity. This opens the door to error conjectures. 


\section{Inferential scepticism and the problem of reflective awareness}

The bearing of the problem of reflective awareness on ToIS isn't devastating. If we actually have inferential seemings, their justifying power is likely to remain unchallenged in most cases. For we don't reflect on our mental states and speculate about their possible causes in normal circumstances; we engage in these activities only when we have reasons to do it. Consequently, the processes described in the former section are bound not to take place, normally, when we draw inferences. I will now argue that, nonetheless, because of the problem of reflective awareness, the antisceptical bite of ToIS is importantly limited in the same way in which PC's is.

Huemer (2016) thinks that ToIS can be adduced to defuse two important types of sceptical arguments. The arguments of the first type aim to conclude that we have no inferentially justified belief because any attempt to acquire it would catch us in a vicious infinite regress. A basic case of this type starts from the familiar assumption that $S$ can have a belief that $P$ is inferentially justified by a belief that $E$ only if $S$ sees that $E$ supports $P$. This necessary condition is interpreted - in the argument - as one that requires $S$ to have a belief that $E$ supports $P$, inferentially justified by some other belief that $E_{1}$ of $S$. Since this necessary condition applies to any inferentially justified belief the argument continues - it must also apply to $S$ 's very belief that $E$ supports $S$, inferentially justified by $E_{1}$. Therefore, $S$ can have this inferentially justified belief only if $S$ possesses a further belief that $E_{1}$ supports the proposition [ $E$ supports $P$ ], inferentially justified by another belief that $E_{2}$. But then, again, $S$ can have the last inferentially justified belief only if $S$ entertains another belief that $E_{2}$ supports the proposition $\left[E_{1}\right.$ supports the proposition $[E$ supports $\left.P]\right]$, inferentially justified by another belief that $E_{3}$. This regress is endless. Since $S$ cannot entertain an endless number of beliefs, $S$ won't satisfy a necessary condition for having an inferentially 
justified belief. So — the argument concludes - S cannot have any inferentially justified belief (cf. Huemer [2016, 148]). ${ }^{18}$

ToIS defuses arguments of this sort by rejecting the interpretation of the necessary condition for inferentially justified belief presupposed by the sceptic. On ToIS, all what $S$ needs to have in order to see that $E$ supports $P$ is just a seeming that $E$ supports $P$. This alternative reading stops the regress (cf. $[2016,153])$.

The problem of reflective awareness as such doesn't undermine this antisceptical consequence of ToIS. As stressed, we seldom reflect on our inferential seemings and speculate about their causes. Consider nevertheless a subject $S$ who infers $P$ from $E$, where $E$ is justified for $S$. Imagine that $S$ happens to be reflectively aware of her seeming that $E$ supports $P$, and that $S$ conceives of some possible explanations of it entailing that the seeming is deceptive. If $S$ cannot rule out these conjectures, $S$ will lose the justification of her belief that $P$. But no infinite regress would necessarily start in this case.

The sceptical arguments of the second type that ToIS is meant to defuse are no less worrying than the former arguments. Suppose $S$ justifiedly believes $E$, sees that $E$ supports $P$, and thereby believes $P$. These sceptical arguments maintain, again, that $S$ 's belief that $P$ cannot be inferentially justified because $S$ cannot meet a crucial condition. Specifically, they say that $S$ 's seeing that $E$ supports $P$ could make the required contribution to the inferential justification of $S$ 's belief that $P$ - to the effect that this belief is justified - only if $S$ had independent justification for taking her seeing that $E$ supports $P$ to be trustworthy. These arguments conclude that since $S$ cannot have this independent justification, $S$ cannot have inferential justification for $P .{ }^{19}$

\footnotetext{
18 See also Fumerton (1995, 187-190).

19 Although Huemer (2016) doesn't explicitly state arguments of this type, the final paragraph of his paper indicates that he has them in mind.
} 
One might try to rebut objections of this sort by insisting that $S$ can and does typically possess independent justification for taking what she sees to be correct. But this is admittedly questionable. For it is questionable that $S$ could justifiedly rule out all relevant error conjectures she might think of. Let's distinguish between ordinary error conjectures and (proper) sceptical conjectures. Any ordinary error conjecture simply specifies that $S$ has made a cognitive mistake that $S$ has not detected or cannot detect in her current circumstances. This doesn't entail that $S$ couldn't find evidence revealing her mistake or ruling out that she has made a mistake, if she were lucky enough or investigated sufficiently the issue. On the other hand, a sceptical conjecture is an error conjecture that specifies that $S$ has made an undetectable cognitive error - one that $S$ couldn't discover or rule out no matter how much or how deep $S$ might investigate (cf. Klein 2008: $§ 1)$.

Consider again the ordinary error conjecture that $S$ 's seeing that $E$ supports $P$ is a deceptive representation caused by an incipient mental disorder. $S$ could rule out this conjecture by taking the negative outcome of a medical test as contrary evidence. However, evidence of this type will lose any significance as $S$ turns to the sceptical conjecture that, say, $S$ 's seeing that $E$ supports $P$ is a deceptive representation caused by a Cartesian demon that endeavours to make $S$ 's deception and its own existence undetectable to $S$. It is hard to imagine the sort of evidence that $S$ could find to rule out a hypothesis of this type.

Huemer believes we can refute sceptical arguments invoking error conjectures of any type by responding as follows:

Since we are justified in trusting our appearances unless and until we acquire grounds for distrusting them, we have an easy explanation of why most inferential beliefs are justified... It would then be the skeptic's burden to show the appearance to be untrustworthy. $(2016,159)$ 
In short, Huemer interprets 'seeing that...' as 'having a seeming that...' and emphasizes that it is false that $S$ 's seeming that $E$ supports $P$ can give its crucial contribution to the inferential justification of $S$ 's belief that $P$ only if $S$ has independent justification for taking her seeming to be trustworthy. The truth is that $S$ 's seeming that $E$ supports $P$ contributes to $S$ 's inferential justification of $P$ by default, unless $S$ is given reasons to distrust it. $^{20}$

I find this rejoinder plausible when $S$ stands for an ordinary, unreflective individual who is not afflicted by sceptical misgivings. If ToIS is true, in the face of the sceptic, ordinary subjects, who are not accustomed to reflect on their inferential seemings and speculate about their causes, will normally have inferential justification. Despite this important result, it appears to me that the truth of ToIS cannot benefit reflective subjects — perhaps epistemologists — who engage with sceptical arguments of the sort just considered in the attempt to reject them.

Imagine that $S$ justifiedly believes $E$, sees that $E$ supports $P$, and thereby believes $P$. Consider the following sceptical argument: since $S$ cannot find independent justification for ruling out the conjecture that $(S H) S$ 's seeing that $E$ supports $P$ is a deceptive representation induced by a Cartesian demon, $S$ 's belief that $P$ isn't inferentially justified. Now let's assume that ToIS is true and let's interpret 'sees that...' as 'has a seeming that...' Suppose $S$ engages with the above sceptical argument. $S$ can do so only if she grasps how the objection puts her inferential justification for $P$ at risk. $S$ can do this only if she is reflectively aware of her inferential seeming that $E$ supports $P$ and appreciates that $S H$ can possibly explain its occurrence as a case of deceptive representation. Once these two conditions are satisfied - despite ToIS $-S$ 's belief that

${ }^{20}$ In the above quotation Huemer writes that 'we are justified in trusting our appearances' unless we acquire grounds to distrust them. Huemer is speaking loosely here. For one of the celebrated strengths of appearances is that their justifying power doesn't require justification for trusting them. Huemer must mean that our appearances have justifying power by default unless we have reasons to distrust them. 
$P$ can be inferentially justified only if $S$ has independent justification for ruling out $S H$, which is just what the inferential sceptic contends.

\section{Possible responses by ToIS's advocates}

Let me now outline and appraise possible lines of response that advocates of ToIS might be tempted to pursue. ${ }^{21}$ (Since advocates of PC might put forward very similar responses when pressed by the sceptic, my remarks also apply to them with minimal changes.)

To begin with, supporters of ToIS might contend that $S$ could justifiedly rule out all the error conjectures conceivable by $S$ through bootstrapping or via epistemically circular reasoning. ${ }^{22}$ These forms of arguments assume (disputably) that $S$ 's justification for ruling out the error conjectures need not be independent of $S$ 's seemings but, rather, can originate from them. Suppose $S$ has a seeming that $E$ supports $P$. By applying bootstrapping, $S$ would first form a belief that $E$ supports $P$, non-inferentially justified through $\mathrm{JS}^{23}$ by her inferential seeming that $E$ supports $P$. Then, $S$ would deduce from this justified belief, and so would justify, the belief that $S H$ is false, where $S H$ is any error conjecture that denies that $E$ supports $P$.

By applying epistemic circular reasoning, $S$ would first form a long series of conjunctive beliefs like these:

I have a seeming that $E_{1}$ supports $P_{1}$ and $E_{1}$ actually supports $P_{1}$,

I have a seeming that $E_{2}$ supports $P_{2}$ and $E_{2}$ actually supports $P_{2}$,

I have a seeming that $E_{k}$ supports $P_{k}$ and $E_{k}$ actually supports $P_{k}$.

${ }^{21}$ I'm grateful to a referee of this Journal for inviting me to consider this issue and suggesting possible responses.

${ }^{22}$ For general discussion about bootstrapping and epistemic circularity see for instance Cohen (2005, 2010), Weisberg (2012) and Lammenranta (2018).

${ }^{23}$ It is quite natural to presume that the advocates of ToIS would endorse PC. 
The first conjunct of each conjunction would be justified introspectively by $S$ 's reflecting on her seeming that $E_{n}$ supports $P_{n}$, and the second conjunct would be noninferentially justified through JS by her seeming that $E_{n}$ supports $P_{n}$. From this long series of conjunctive beliefs $S$ would then infer and justify by induction the belief that her inferential seemings are generally reliable (in the sense that their contents are true most of the time). From it, $S$ would further deduce and justify the belief that $S H$ is false, where $S H$ is any error conjecture that denies the reliability of $S$ 's seemings.

I think that neither strategy would have a good chance to succeed. It appears straightforward to me that one cannot establish that a given experience is accurate by examining only that experience and without considering independent evidence.

Furthermore, it is intuitive that one cannot establish that experiences of a certain type are reliable by inspecting only a series of those experiences and without considering independent evidence. However, these are precisely the sorts of things that bootstrapping and epistemically circular reasoning would enable us to do if they were accepted as valid inferential patterns. Since bootstrapping and inferentially circular reasoning are counterintuitive (cf., White [2006], Wright [2007], Vogel [2008], Cohen [2005, 2010], Weisberg [2012] and Siegel and Silins [2015]), ${ }^{24}$ many if not most epistemologists would dismiss this line of reply as flawed or very suspect.

Let's turn to an alternative strategy. Advocates of ToIS might be tempted to claim that $S$ could acquire independent justification for ruling out any error conjecture $\mathrm{SH}$ she might conceive of, for $S$ would normally have a seeming that Not-SH is true or probable for any such $S H$. This line of response looks more promising than the former. I

${ }^{24}$ Some of these authors claim that PC is problematic because it enables bootstrapping and epistemically circular reasoning. I doubt this is true. I think that a subject $S$ couldn't competently use inferences of these types to try to rule out error conjectures without falling prey to the problem of reflective awareness and thus losing her initial noninferential justification. So it appears true that PC doesn't enable bootstrapping or epistemically circular reasoning. 
don't find serious objections when $\mathrm{SH}$ stands for an ordinary error conjecture. Suppose $S$ has a seeming that $E$ supports $P$, where $E$ and $P$ are mathematical statements. Imagine that after becoming reflectively aware of this seeming, $S$ conceives of an error conjecture $\mathrm{SH}$ stating that, say, her seeming is deceptive because she has inadvertently ingested a drug that hampers her mathematical reasoning. $S$ would normally have some evidence $E^{*}$ (e.g., all justified beliefs of $S$ about drugs, their effects and their availability) from which she could infer that $N o t-S H$ is probable. Accordingly, $S$ would have an inferential seeming that $\mathrm{Not}-\mathrm{SH}$ is probable in light of $E^{*}$. Alternatively, it might happen that upon appraising $S H, S$ would come to entertain a seeming that NotSH is probable without drawing any inference. Huemer $(2016,145,158)$ acknowledges that phenomena of this type are psychologically possible and indeed quite ordinary; he describes them as cases of justificatory non-inferential dependence of $S$ 's appearances on $S$ 's background information $B$. S's seeming that Not-SH is probable would in these cases be shaped by $B$, and the probability of Not-SH would be relative to $B$. Whether $S$ had an inferential seeming that $\mathrm{Not}-\mathrm{SH}$ is likely given $E^{*}$ or a seeming that $\mathrm{Not}-\mathrm{SH}$ is likely (relative to $B$ ), $S$ would have justification for ruling out $S H$.

Unfortunately, this line of response becomes very problematic when $S H$ is a sceptical conjecture (in the sense specified above), for in this case any seeming that $S$ might attempt to use to rule out $S H$ could be potentially explained by $S H$ itself as a deceptive representation. Suppose for instance $S$ has a seeming that $E$ supports $P$. Imagine that after becoming reflectively aware of it, $S$ conceives of a sceptical conjecture $\mathrm{SH}$ according to which her seeming is deceptive because it has been caused by a vicious demon that gets pleasure from secretly misleading $S$ 's reasoning. If $S$ also entertains an appearance - inferential or a non-inferential - that $N o t-S H$ is probable, ${ }^{25} S$

\footnotetext{
${ }^{25}$ For example, $S$ might have an inferential appearance that $N o t-S H$ is probable in light of $S H$ 's being far-fetched and overcomplicated, or a non-inferential appearance that $\mathrm{Not}-\mathrm{SH}$ is probable relative to $S$ 's scientific background information.
} 
will have justification for ruling out $S H$. So far so good. The problem is this: since $S$ is by assumption a reflective subject, it would be exceedingly easy for $S$ to become reflectively aware of her seeming that Not-SH is probable and appreciate that this very seeming could be potentially explained by $\mathrm{SH}$ as a misleading representation induced by the demon to conceal its mischievous activity. This would destroy $S$ 's justification for believing Not-SH and disbelieving $S H$ depending on that seeming. Also note that once $S$ appreciates that $\mathrm{SH}$ can potentially explain her seeming that $\mathrm{Not}-\mathrm{SH}$ is probable as a deceptive state, it will be very easy for $S$ to realize that any other appearance she might attempt to use to restore her justification for Not-SH could also be potentially explained by $\mathrm{SH}$ as a deceptive representation induced by the demon. This would disable the justifying power of all these appearances of $S$ in one shot. Given these difficulties, this line of reply appears to me ultimately unviable.

A way to settle the problems just described might be combining ToIS with some version of entitlement theory. Let me briefly explore this possibility. This brings us to the last line of response available to ToIS's advocates that I will consider in this paper. Some epistemologists - prominently, Wright $(2007,2007,2014)$ - maintain that there exists a type of epistemic justification — called by Wright epistemic entitlement (or simply entitlement) - for accepting the logical negation of any sceptical conjecture. ${ }^{26}$ Justification of this type is not based on any evidence of the subject or acquired through any epistemic work made by the subject but it is possessed by all rational thinkers by default as a sort of epistemic right. Accordingly, possessing justification of this type doesn't require the subject to entertain any sort of (perhaps deceptive) appearance. A quite similar view has been put forward by Michael Williams (1996). The thesis that we

${ }^{26}$ Precisely, according to Wright, we are entitled to accept certain hinge propositions (cornerstones or presuppositions) inclusive of these logical negations. Sceptical conjectures are characterized by Wright as error or deception hypotheses such that the evidence in favour or against them can only be none or very little at best. 
have epistemic entitlements seems to trace back to Thomas Reid's Essays on the Intellectual Powers of Man (see Reid [1983]).

To respond to the sceptic, advocates of ToIS might insist that $S$ could have independent justification for ruling out any error conjecture $S H$ she might conceive of. Precisely, they could argue that $S$ would normally have a seeming that $N o t-S H$ is true or probable if $S H$ were an ordinary error conjecture, and that $S$ would be entitled to accept that $N o t-S H$ is true if $S H$ were a sceptical conjecture.

I think that this response to the sceptic would have more chance to succeed than the ones examined before. Wright's entitlement theory — which is probably the most developed view of this sort — has attracted objections of various types. Possibly, the most recurrent criticism holds that what Wright calls entitlement isn't a form of epistemic justification (cf. Pritchard [2005] and Jenkins [2007]). For a survey of objections see Wright (2014). Examining the critical literature on entitlement theory is beyond the scope of this paper. Let me only emphasize that Wright (2014) has made a good effort to address the major objections. For other rejoinders see for example Pedersen (2009) and Vahid (2017).

\section{Conclusion}

I have analyzed Huemer's ToIS, according to which $S$ 's possessing inferential justification requires $S$ to entertain suitable inferential seemings. I have argued that, despite its important epistemological merits, ToIS is affected by a version of the

problem of reflective awareness, which makes $S$ 's inferential justification hostage to sceptical arguments requiring $S$ to have independent justification for ruling out error conjectures. I have suggested that this problem might be surmounted if ToIS were combined with some version of entitlement theory. 


\section{References}

Brogaard, Berit. 2016. "Staying Indoors: How Phenomenal Dogmatism Solves the Skeptical Problem Without Going Externalist.” In Intellectual Assurance: Essays on Traditional Epistemic Internalism, edited by Brett Coppenger and Michael Bergmann, 85-104. Oxford: OUP.

Cohen, Stewart. 2005. "Why Basic Knowledge Is Easy Knowledge.” Philosophy and Phenomenological Research 70: 417-430.

Cohen, Stewart. 2010. “Why Basic Knowledge Is Easy Knowledge.” Philosophical Perspectives 24, Epistemology: 141-159.

Chudnoff, Elijah. 2014. “The Rational Roles of Intuitions.” In Intuitions, edited by Anthony R. Booth and Darrel P. Rowbottom, 9-35. Oxford: OUP.

Fumerton, Richard. 1995. Metaepistemology and Skepticism. Lanham, MD: Rowman \& Littlefield.

Fumerton, Richard. 2015. "What the internalist should say to the tortoise." Episteme 12: 209-217.

Huemer, Michael. 2001. Skepticism and the veil of perception. Lanham, MD: Rowman and Littlefield.

Huemer, Michael. 2006. "Phenomenal Conservatism and the internalist intuition." American Philosophical Quarterly 43: 147-158.

Huemer, Michael. 2007. "Compassionate Phenomenal Conservatism." Philosophy and Phenomenological Research 74: 30-55.

Huemer, Michael. 2011. "Phenomenal conservatism and self-defeat: a reply to DePoe." Philosophical Studies 156: 1-13.

Huemer, Michael. 2013. "Phenomenal Conservatism Uber Alles." In Seemings and Justification: New Essays on Dogmatism and Phenomenal Conservatism, edited by Chris Tucker, 328-350. NY: OUP. 
Huemer, Michael. 2016. “Inferential Appearances.” In Intellectual Assurance: Essays on Traditional Epistemic Internalism, edited by Brett Coppenger and Michael Bergmann, 144-160. Oxford: OUP.

Huemer, Michael. 2018. "Phenomenal Conservatism," Internet Encyclopedia of Philosophy. http://www.iep.utm.edu/phen-con/.

Jenkins, Carrie. 2007. "Entitlement and Rationality." Synthese 157: 25-45.

Klein, Peter. 2015. "Skepticism.” In The Stanford Encyclopedia of Philosophy, edited by Edward N. Zalta http://plato.stanford.edu/entries/skepticism/.

Lammenranta, Markus. 2018. "Epistemic Circularity.” Internet Encyclopedia of Philosophy. http://iep.utm.edu/ep-circ/.

Moretti, Luca. 2015. "Phenomenal conservatism.” Analysis 75: 296-309.

Moretti, Luca. 2018. "Phenomenal conservatism and the problem of reflective awareness." American Philosophical Quarterly 55: 267-280.

Pedersen, Nikolaj. 2009. "Entitlement, value and rationality.” Synthese 171: 443-457.

Pritchard, Duncan. 2005. 'Wittgenstein's On Certainty and Contemporary AntiScepticism." In Readings of Wittgenstein's On Certainty, edited by Daniele Moyal-Sharrock and William H. Brenner, 189-224. London: Palgrave McMillian.

Pryor, James. 2000. “The Skeptic and the Dogmatist.” Nous 34: 517-549.

Pryor, James. 2004. “What's wrong with Moore's argument?” Philosophical Issue 14, Epistemology: 349-378.

Pryor, James. 2018. “The Merits of Incoherence.” Analytic Philosophy 59: 112-141.

Reid, Thomas. 1983. Inquiry and Essays. Indianapolis: Hackett.

Siegel, Susan and Nicholas Silins. 2015. "The Epistemology of Perception.” In Oxford Handbook of Philosophy of Perception, edited by Matthew Matthen, 781-810. Oxford: OUP. 
Tucker, Chris. 2013. "Seemings and Justification: An Introduction”. In Seemings and Justification: New Essays on Dogmatism and Phenomenal Conservatism, edited by Chris Tucker, 1-29. NY: OUP.

Vahid, Hamid. 2017. "Deontological Conservatism and Perceptual Justification." Theoria 83: 206-224.

Vogel, Jonathan. 2008. "Epistemic Bootstrapping." Journal of Philosophy 105: 218239.

Weisberg, Jonathan. 2012. “The bootstrapping problem.” Philosophy Compass 7: 597610.

White, Roger. 2006. "Problems for dogmatism.” Philosophical Studies 131: 525-57.

Williams, Michael. 1996. Unnatural Doubts. Princeton: Princeton University Press.

Wright, Crispin. 2004. “On Epistemic Entitlement: Warrant for Nothing (and Foundations for Free?)" Proceedings of the Aristotelian Society, Supplementary 78: 167-212.

Wright, Crispin. 2007. "Perils of Dogmatism.” In Themes from G. E. Moore: New Essays in Epistemology and Ethics, edited Susanna Nuccetelli, 25-48. Oxford: OUP.

Wright, Crispin. 2014. “On Epistemic Entitlement (II): Welfare State Epistemology.” In Scepticism and Perceptual Justification, edited by Elia Zardini and Dylan Dodd, Ch. 10. New York: OUP. 